\title{
Fotovoltaik (PV) Pompa Sisteminin Bileşenlerinin Hesabı
}

\author{
Ahmet Demir ${ }^{1}$, F. Mertkan Arslan ${ }^{2}$, Hüseyin Günerhan ${ }^{* 3}$ \\ ÖZ
}

Çalışma kapsamında, bir fotovoltaik (PV) pompa sisteminin optimum olarak boyutlandırılması için bir programlama algoritması oluşturulmuştur. Boyutlandırma algoritması, sistemdeki enerji dengesini temel alarak çalışmaktadır. Algoritma, hem akülü hem de aküsüz PV pompa sisteminin boyutlandırılması için uygun olarak modellenmiștir. Akü içeren PV pompa sistemleri için optimizasyon, aküye giren-çıkan enerjilerin dengesi ile iterasyon yöntemi kullanılarak gerçekleşmektedir. Akü içermeyen sistemler için optimizasyon, pompanın kullandığı enerjiyi karşılayabilecek PV panel alanının bulunmasını temel almaktadır. Çalışmada oluşturulan algoritma, Temmuz ayında Manisa-Salihli ilçesinde 1 hektarlık alanda mısır bitkisi için uygulanmıştır. Bitkinin sulanması için damlama sulama yöntemi kullanıldığı kabulü yapılmıştır. Ek olarak, kuyu için gerekli kabuller ve varsayımlar yapıldıktan sonra, pompaya gereken güc $1,5 \mathrm{~kW}$ ve debi $9,55 \mathrm{~m}^{3} / \mathrm{h}$ olarak hesaplamalara eklenmiştir. Sonuç olarak, sistemde akünün bulunması dahilinde toplam 23 adet PV panel gerekli iken, akünün olmaması durumunda 36 adet PV panel gerekli olduğu hesaplanmıştır. Gerekli akü miktarı ise 3 adet olarak bulunmuştur. Bu sonuçlara göre, sistem içerisinde akü kullanılması halinde, gerekli PV panel miktarının önemli ölçüde düşürüldüğü hesaplanmıştır. Ek olarak, bir diğer önemli sonuç ise, sistemde akü bulunmaması durumunda, PV panelin elde edebileceği potansiyel enerji miktarının yarısı israf edilmektedir. Ancak akü kullanılması durumunda ise, israf edilecek bu enerji aküler tarafından toplanarak, sistemin daha optimize edilebilir bir hal alması sağlanmaktadır.

Anahtar Kelimeler: Güneş enerjisi, fotovoltaik pompa, boyutlandırma algoritması.

\section{Creating the Sizing Algorithm of a Photovoltaic Pump System}

\begin{abstract}
In this study, an algorithm has been created to optimally sizing a photovoltaic pump system. The sizing algorithm works based on the energy balance in the system. The algorithm is suitable for the sizing of both battery-powered and battery-free photovoltaic (PV) pump systems. For PV pump systems containing batteries, optimization takes place using the iteration method with the balance of energies charging or discharging the battery. Optimization for battery-free systems is based on the availability of PV panel area to meet the energy used by the pump. The algorithm created in the study was applied for corn plant in 1 hectare area in Manisa - Salihli district in July. It is assumed that drip irrigation method is used for watering the plant. In addition, after the necessary assumptions are made for the well, the power of the pump is added to the calculations as $1.5 \mathrm{~kW}$ and the flow rate is $9,55 \mathrm{~m}^{3} / \mathrm{h}$. As a result, it was calculated that a total of 23 panels are required within the system with battery and on the other hand, $36 \mathrm{PV}$ panels are required in the absence of a battery. In addition, the required battery amount was found to be 3 . According to these results, if the battery is used in the system, the amount of PV panels required is reduced significantly. In addition, another important result is that half the amount of potential energy that the PV panel can obtain is wasted if there is no battery in the system. However, if the battery is used, this energy to be wasted is collected by the batteries and the system is provided to become more optimized.
\end{abstract}

Keywords: Solar energy, photovoltaic pump system, sizing algorithm

$\begin{array}{ll} & \\ \text { "İletişim Yazarı } & \\ \text { Geliş/Received } & : 09.06 .2020 \\ \text { Kabul/Accepted } & : 18.08 .2020\end{array}$

1 Ege Üniversitesi, Fen Bilimleri Enstitüsü, Makina Mühendisliği Anabilim Dalı, Bornova-İzmir ademir@grundfos.com, Orcid:0000-0002-3386-0926

2 Ege Üniversitesi, Fen Bilimleri Enstitüsü, Makina Mühendisliği Anabilim Dalı, Bornova-İzmir mertkan.arslan@gmail.com, Orcid: 0000-0001-8359-7743

3 Ege Üniversitesi, Mühendislik Fakültesi, Makina Mühendisliği Bölümü, Bornova-İzmir huseyin.gunerhan@ege.edu.tr, Orcid: 0000-0003-4256-2418 


\section{EXTENDED ABSTRACT}

In this study, an algorithm has been created to optimally sizing a photovoltaic (PV) pump system. The sizing algorithm works based on the energy balance in the system. The algorithm is suitable for the sizing of both battery-powered and battery-free photovoltaic pump systems. For PV pump systems containing batteries, optimization takes place using the iteration method with the balance of energies charging or discharging the battery. Optimization for battery-free systems is based on the availability of PV panel area to meet the energy used by the pump. The algorithm can be applied to all regions and plants. In the study, firstly, the radiation on the sloped surface was calculated, then the water requirement of the plant was determined and the submersible pump that could meet this requirement was selected. Then, the calculation steps of the optimum PV panel surface area and battery amount that can handle the load of this pump are applied.In the next step, the sizing algorithm was validated. Finally, a sample study has been carried out. In the study, the sizing algorithm of the photovoltaic pump system was completed in the presence and absence of batteries. With this study, it has been shown that the amount of PV panels required for the system in the presence and absence of battery is quite different. In addition, this study is a preliminary step for economic analysis to determine which system is more advantageous. The algorithm created in the study was applied for corn plant in 1 hectare area in Manisa - Salihli district in July. It is assumed that drip irrigation method is used for watering the plant. In addition, after the necessary assumptions are made for the well, the power of the pump is added to the calculations as $1.5 \mathrm{~kW}$ and the flow rate is $9,55 \mathrm{~m}^{3} / \mathrm{h}$. As a result, it was calculated that a total of 23 panels are required within the system with battery and on the other hand, $36 \mathrm{PV}$ panels are required in the absence of a battery. In addition, the required battery amount was found to be 3 . According to these results, if the battery is used in the system, the amount of PV panels required is reduced significantly. In addition, another important result is that half the amount of potential energy that the PV panel can obtain is wasted if there is no battery in the system. However, if the battery is used, this energy to be wasted is collected by the batteries and the system is provided to become more optimized. 


\section{GÍRİş}

Güneş enerjisi, elektrik şebekesinin bulunmadığı ve/veya bulunduğu bölgelerde aydınlatma, pompalama, vb. düzeneğe güç vermek için yaygın olarak kullanılmaktadır. Güneş enerjisinin en önemli avantajları; bu kaynağın tükenmez olması ve kullanım güvenliği sunmasıdır [1]. Bununla birlikte, fotovoltaik (PV) sisteminin dezavantajı ise geleneksel enerji kaynaklarına kıyasla yüksek maliyetidir. Bu yüzden PV panel içeren sistemlerinin optimizasyon çalışmalarının yapılması önem teşkil etmektedir [2]. Genel olarak, PV sistem boyutlandırması, sezgisel, analitik, sayısal ve yapay zekâ yöntemleri kullanılarak gerçekleştirilebilir. Sezgisel yöntem, en kritik aya veya ortalama aylık güneş 1şınımına dayanan en basit yöntemdir. Bununla birlikte, bu yöntem PV pompa sisteminin aşırı yüksek veya düşük boyutlandırılmasına yol açabilir, bu da maliyeti ve/veya sistemin güvenilirliğini azaltabilir. Sistem büyüklügüünün analitik bir yöntem temelinde hesaplanması sezgisel yöntemden daha basit ve daha doğrudur, ancak bu denklemlerin karmaşıklığı bu yöntemin temel dezavantajıdır [3].

PV pompalama sistemleri, elektrik şebekelerine hiçbir bağlantısı olmayan veya sınırlı bağlantısı olan kırsal alanlarda suya erişim sağlamak için en kritik çözümlerden biridir. PV panel ile çalışan su pompalama sistemlerinin, kullanım güvenliği, sağlamlık ve çevre ile uyum gibi birçok avantajları vardır [4]. İyi tasarlanmış yenilenebilir enerji kaynaklı bir su pompalama sistemi, Diesel jeneratör veya şebekeye bağlı su pompalama sistemlerine göre hem yüksek verimlilik hem de ekonomi açısından rekabetçi olabilmektedir. PV pompa sistemleri esas olarak PV paneller, elektrik motoru ve pompa setinden oluşmaktadır. Ancak, sistem gereksinimlerine bağlı olarak, akü ve şarj regülatörleri de sisteme eklenebilir. Motor AC (alternatif akım) ile çalışıyorsa, AC-DC dönüştürücüsüne ihtiyaç vardır. DC (doğru akım) ile çalıştırılırsa da DC-DC dönüştürücüleri sisteme eklenebilir [5].

Birçok araştırmacı, PV pompa sisteminin boyutlandırılması, ekonomik performansının incelenmesi ve çevresel fizibilite çalışmaları üzerine odaklanmışlardır [6]. Kaldellis ve diğerleri, saatlik meteorolojik veriler yardımı ile PV pompa boyutlandırması yapmışlardır ve deneysel veriler ile kıyaslama yapmışlardır [7]. Bakelli ve diğerleri, PV pompa ile su tank1 modellemesini LPSP (the loss of power supply probability) konseptini kullanarak bir çalışma gerçekleştirmişlerdir [8]. Yahyaoui ve diğerleri, PV pompa sistemlerinin optimum boyutlandırılması için enerji dengesini kullanarak bir algoritma oluşturmuşlardır [9] . Salam ve diğerleri, PV pompa sistemi için hazır PV boyutlandırma programı (HOMER) kullanarak bir çalışma yapmışlardır [10]. Ma ve diğerleri tekno-ekonomik optimizasyon yöntemi kullanarak sistem modellemesi çalışması gerçekleştirmişlerdir [11]. Muhsen ve diğerleri ise, hibrit çok kriterli karar verme yöntemlerini ve sistemin ekonomik verilerini değerlendirerek bir boyutlandırma çalışması yayınlamışlardır [3].

Çalışmada, akü varlığında ve yokluğunda fotovoltaik pompa sisteminin boyutlandır- 
ma algoritması tamamlanmıştır. Bu çalışma ile sistemin akü varlığında ve yokluğunda sisteme gereken PV panel miktarlarının oldukça farklı olduğu gösterilmiştir. Ek olarak bu çalışma, hangi sistemin daha avantajlı olduğunun belirlenmesi için ekonomik analizlerinin yapılması için de bir ön adım olmaktadır.

Çalışma kapsamında, öncelikle, eğik yüzeye gelen ışınım hesabı yapılacaktır, ardından bitkinin su ihtiyacı belirlenip bu ihtiyacı karşılayabilecek dalgıç pompa seçimi yapılacaktır. Sonraki adımda, bu pompanın yükünü kaldırabilecek optimum PV panel yüzey alanı ve akü miktarının hesaplama adımları verilecektir. Daha sonra oluşturulan algoritma için örnek çalışma gerçekleştirilecektir.

Algoritma programı, araştırmacılar ve ilgili sektördeki kişiler için yardımcı bir kaynak olacağı amaçlanmıştır.

\section{FOTOVOLTAIK (PV) POMPA SISTEMININ BILEŞENLERINIIN HESABI}

\subsection{Eğik Yüzeye Gelen Işınım Hesabı}

PV pompanın komponentlerinin hesaplanabilmesi için yataya gelen güneş 1şınımının teorik olarak hesaplanması gerekmektedir. Eğik yüzeye gelen saatlik ışınım, izotropik gök yaklaşımı ile hesaplanması Denklem 1 ile verilmiştir [12].

$$
I_{T}=I_{b} R_{b}+I_{d}\left(\frac{1+\cos \beta}{2}\right)+I \rho_{g}\left(\frac{1-\cos \beta}{2}\right)
$$

Denklem 1 içerinde verilen, $\beta$, yüzey eğimini ve $\rho_{g}$, yerin aklık derecesini temsil

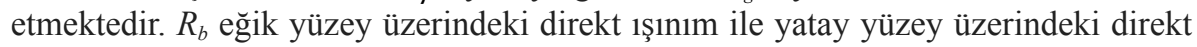
1şınım oranıdır. Ayrıca, I, dik yüzeye gelen toplam saatlik ışınım değeridir. Tüm hesaplamalara öncelikle, sistemin kurulacağı bölgenin aylık ortalama günlük ışınım verilerinin $(\bar{H})$ elde edilmesi ile başlanmaktadır. $\bar{H}$ kullanılarak saatlik direkt $\left(I_{b}\right)$ ve yayılı $\left(I_{d}\right)$ ışınımın hesaplanması için Denklem 2'den Denklem 12'ye kadar olan eşitliklerin kullanılması gerekmektedir.

Günlük atmosfer dışı aylık ışınım değeri ve bu değere bağlı olan aylık ortalama açıklık endeksi Denklem 2 ve Denklem 3 ile hesaplanabilir [12].

$H_{o}=\frac{24 \times 3600 G_{S C}}{\pi}\left(1+0,033 \cos \frac{360 n}{365}\right) x\left(\cos \phi \cos \delta \sin \omega_{s}+\frac{\pi \omega_{s}}{180} \sin \phi \sin \delta\right)$

Denklem 2 ile verilen $G_{S C}$, güneş sabitidir ve değeri $1367 \mathrm{~W} / \mathrm{m}^{2}$ 'dir. Denklem içerisindeki $n, \phi, \delta, \omega_{s}$ sırası ile, ayın gün sayısı, bölgenin enlemi, deklinasyon açısı ve günbatımı saat açısıdır $\left(\cos \omega_{s}=-\tan \phi \tan \delta\right)[12]$. 


$$
\bar{K}_{T}=\frac{\bar{H}}{\bar{H}_{o}}
$$

Günlük ortalama aylık yansıyan ışınım, aylık ortalama açıklık endeksinin bir fonksiyonu olarak Denklem 4 ve Denklem 5 kullanılarak hesaplanabilir. Hesaplamalarda, ilgili ayın ortalama gününün $H_{o}$ değeri ve o ayın $\bar{H}_{o}$ değeri birbirine çok yakın değerler olduğu için $\bar{H}_{o}$ değeri yerine $H_{o}$ denklemi kullanılmıştır [12].

Eğer, $\omega_{S} \leq 81,4^{\circ}$ ve $0,3 \leq \bar{K}_{T} \leq 0,8$ ise;

$\bar{H}_{d}=\left(1,391-3,560 \bar{K}_{T}+4,189 \bar{K}_{T}^{2}-2,137 \bar{K}_{T}^{3}\right) \bar{H}$

Eğer $\omega_{s}>81,4^{\circ}$ ve $0,3 \leq \bar{K}_{T} \leq 0,8$ ise;

$\bar{H}_{d}=\left(1,311-3,022 \bar{K}_{T}+3,427 \bar{K}_{T}^{2}-1,821 \bar{K}_{T}^{3}\right) \bar{H}$

Saatlik toplam ışınım, aylık ortalama günlük ışınım kullanılarak Denklem 6 ile hesaplanabilir [12].

$I=r_{t} \bar{H}$

Denklem 6 içerisindeki $I$ ile $\bar{H}$ oranını oluşturan $r_{i}$ Denklem 7 ile verilmiştir.

$$
r_{t}=\frac{\pi}{24}(a+b \cos \omega) \frac{\cos \omega-\cos \omega_{s}}{\sin \omega_{s}-\frac{\pi \omega_{s}}{180} \cos \omega_{s}}
$$

Denklemdeki $a$ ve $b$ katsayıları Denklem 8 ve 9 ile verilmiştir. Denklem 7 içerisinde belirtilen $\omega$ değeri; Dünyanın kendi ekseni etrafında saatte $15^{\circ}$ dönmesi nedeniyle güneşin, yerel meridyenin doğusunda veya batısında açısal yer değiştirmesidir. Öğleden önce negatif, öğleden sonra pozitif olmaktadır [12].

$$
\begin{aligned}
& a=0,409+0,5016 \sin \left(\omega_{s}-60\right) \\
& b=0,6609-0,4767 \sin \left(\omega_{s}-60\right)
\end{aligned}
$$

Aynı şekilde, saatlik toplam yayılı ışınım, aylık ortalama günlük yayılı 1şınım değerleri kullanılarak Denklem 10 kullanılarak hesaplanabilir.

$$
I_{d}=r_{d} \bar{H}_{d}
$$

Denklem 6 içerisindeki $r_{d}$ değişkeni Denklem 11 ile gösterilmiştir [12].

$$
r_{d}=\frac{\pi}{24} \frac{\cos \omega-\cos \omega_{s}}{\sin \omega_{s}-\frac{\pi \omega_{s}}{180} \cos \omega_{s}}
$$


Saatlik toplam direkt ışınım değeri ise Denklem 12 ile hesaplanabilir [12].

$$
I_{b}=I-I_{d}
$$

Böylelikle elde edilen tüm değişkenler Denklem 1 içerisine yerleştirilir ve eğik yüzeye gelen saatlik (veya daha kısa süreli) 1şınım değeri elde edilebilir. Gün içerisinde gelen tüm eğik düzleme gelen saatlik ışınım değeri $I_{t}$ değerleri toplanması halinde $H_{T}$ değeri bulunmaktadır [12].

\subsection{Fotovoltaik (PV) Panel Modeli}

Eğik düzlemli PV güneş panelinin çıkış gücü Denklem 13 ile verilmiştir.

$$
P_{p v}=\eta_{P V} A_{P V} I_{T}
$$

Denklem 13 ile verilen $\eta_{P V}$, PV panel verimi, $A_{P V}$ yüzey alanı olarak nitelendirilmektedir. Denklem 14 ile PV panel verimi hesaplanabilmektedir $[8,13]$.

$$
\eta_{P V}=\eta_{r} \eta_{p c}\left[1-\beta_{P V}\left(T_{c}-T_{c r e f}\right)\right]
$$

$\eta_{r}$ referans panel verimliliği, $\eta_{p c}$ güç şartlandırma verimidir ve maksimum güç izleyici (MPPT) mükemmel olarak kabul edilirse bu değer 1 olarak alınabilir. $\eta_{r}$ değeri 1 olarak hesaplamalara dahil edilmiştir. $\beta_{P V}$ PV panel sıcaklık katsayısıdır. Silikon hücreler için bu değer sıcaklık başına genellikle 0,004-0,006 arasında değişebilmektedir. Çalışma kapsamında bu değer 0,004 olarak kullanılmıştır. $T_{c}$ hücre sıcaklığ 1 ve $T_{\text {cref }}$ referans hücre sıcaklığıdır. Hücre sıcaklığı Denklem 15 ile hesaplanabilir [8].

$$
T_{c}=T_{a}+\left[\frac{(N O C T-20)}{800}\right] I_{T}
$$

Denklem 15 ile verilen $T_{a}$ hava sıcaklığını ve NOCT, "nominal hücre çalışma sıcaklığını” temsil etmektedir. Çalışma kapsamına kullanılacak olan panel özellikleri Tablo 1 ile verilmiştir $[8,13]$.

\subsection{Bitkinin Su İhtiyacı}

PV pompa sisteminin seçimi için bitkinin türünün ve bu bitkinin su ihtiyacının belirlenmesi gerekmektedir. Bitkinin su ihtiyacının belirlenmesi için (16-21) numaralı denklemler kullanılmıştır.

Bitkinin su ihtiyacının hesaplamalarında, sulama yönteminin belirlenmesi önemli bir faktördür. Yağmurlama yönteminin kullanıldığı sistemlerde, net sulama suyu ihtiyacı 
$\left(d_{n}\right)$ Denklem 16 ile verildiği gibi, bitkinin su tüketiminden ETc etkili yağış miktarının $\left(P_{e}\right)$ çıkarılması ile hesaplanmaktadır [15].

Tablo 1. PV Panel Verileri [14]

\begin{tabular}{|c|c|c|c|}
\hline PV markası & SunPower (SPR-210-BLK) & PV panel tipi & Monokristal \\
\hline Max Güç & $210 \mathrm{~W}$ & Sıcaklık katsayısı & $\% 0,38$ \\
\hline Nominal Voltaj & $40 \mathrm{~V}$ & Açık devre voltajı & $47,7 \mathrm{~V}$ \\
\hline Nominal Akım & $5,25 \mathrm{~A}$ & Kısa devre Akımı & $5,75 \mathrm{~A}$ \\
\hline Verimlilik $\left(\eta_{p c}\right)$ & $\% 16,9$ & Alanı & $1,248 \mathrm{~m}^{2}$ \\
\hline NOCT & $45^{\circ} \mathrm{C}$ & Invertör verimi $\left(\eta_{i v v}\right)$ & $\% 97,5$ \\
\hline
\end{tabular}

Tablo 2. Sulama Yöntemlerine Göre Su Uygulama Verimleri [15]

\begin{tabular}{|l|c|}
\hline Yöntem & $E_{a}$ (\%) \\
\hline Taşınabilir yağmurlama sulama & 70 \\
\hline Sabit yağmurlama sulama & 75 \\
\hline Dönme eksenli ve doğrusal yağmurlama ile sulama & 82,5 \\
\hline Ağaçaltı mikro yağmurlama sulama & 87,5 \\
\hline Yüzey damla sulama & 87,5 \\
\hline Yüzeyaltı damla sulama & 90 \\
\hline
\end{tabular}

$d n=E T c-\mathrm{P}_{e}$

Damlama yöntemiyle sulamada ise, su tüketimi Denklem 17 ile verilen eşitlik ile düzeltilmiş olarak kullanılmalıdır.

$T=\operatorname{ETc}\left(\frac{P s}{85}\right)$

Denklem 17 ile verilen $T(\mathrm{~mm})$ düzeltilmiş bitki su tüketim miktarı ve PS (\%) bitki tarafından gölgelenen alandır. [15] numaralı referansa göre, $P s$ değeri için, tarla bitkileri ve sebzelerde \%80, bağ ve sık dikim yapılan meyve ağaçlarında (sıra aralığ 4 m’den sık) \%75, geniş dikim aralıklarına sahip meyve ağaçlarında (sıra aralığı $4 \mathrm{~m}$ ve daha geniş) ise \%70 alınması uygun görülmüştür. Bitkinin su ihtiyacı ETc, bitki gelişme dönemleri olan başlangıç, gelişme, orta ve son dönem uzunluklarına göz önü- 
ne alınarak belirlenir. Çalışmada, aylar 10 günlük, üç döneme ayrılmıştır. Damlama sulama için net sulama suyu ihtiyacı Denklem 18 ile hesaplanabilir [15].

$d n=T-P_{e}$

Toplam sulama suyu ihtiyacı ise, Denklem (19) ile verilmiştir. Denklemdeki $E_{a}$ su uygulama verimi (Tablo 2 ile verilmiştir), $E_{e}$ ise su iletim verimidir (Basıcçlı borulu sulama düzeneklerinde bu değer \%98 alınmaktadır) [15].

$d t=\frac{d n}{\left(E_{a} E_{c}\right)}$

Manisa ilinin Salihli ilçesinde 1 hektar alan için mısır bitkisinin Temmuz ayındaki toplam sulama suyu ihtiyacı Denklem 19 kullanılarak toplam 227,1 $\mathrm{m}^{3}$ olarak hesaplanmıştır (Tablo 3). Bitki için 12 ayın en yüksek su ihtiyacı gerektiren ay Temmuz ayı olduğu için sulama suyu ihtiyacı bu aya göre seçilmiştir [15]. Saatteki sulama miktarının bulunabilmesi için Manisa ilindeki Temmuz ayının ortalama güneşlenme süresi olan 10,5 saat hesaplamalara dahil edilmiştir [16]. Böylelikle, pompanın debisi $7 \mathrm{~m} 3 / \mathrm{h}$ olarak hesaplanmıştır. Ancak, çalışma kapsamında hesaplanan bu değere \%25 emniyet payı eklenmiştir. Böylelikle pompa sistemin debisi $8,75 \mathrm{~m}^{3} / \mathrm{h}$ olmaktadır.

Tablo 3. Temmuz ve Ağustos Ayı İçin Sulama Suyu İhtiyacı Hesaplamaları [15] .

\begin{tabular}{|l|c|c|c|c|c|c|}
\hline \multirow{2}{*}{ Bitki: Mısır } & \multicolumn{3}{|c|}{ TEMMUZ } & \multicolumn{3}{c|}{ AĞUSTOS } \\
\cline { 2 - 7 } Sulama tipi: Damlama & I.DÖNEM & II.DÖNEM & III.DÖNEM & I.DÖNEM & II.DÖNEM & III.DÖNEM \\
\hline $\begin{array}{l}\text { Bitki su tüketimi } \\
\text { (Etc) (mm) }\end{array}$ & 71,1 & 71 & 76,8 & 66,6 & 63,6 & 62,2 \\
\hline $\begin{array}{l}\text { Damlama için bitki su } \\
\text { tüketimi (T) (mm) }\end{array}$ & 66,9 & 66,8 & 72,3 & 62,7 & 59,9 & 58,5 \\
\hline Yağış (P) (mm) & 2,4 & 3,2 & 1,5 & 2,8 & 1,4 & 1,6 \\
\hline $\begin{array}{l}\text { Etkili yağı̧ (Pe) } \\
\text { (mm/gün) }\end{array}$ & 1,9 & 2,6 & 1,2 & 2,3 & 1,1 & 1,3 \\
\hline $\begin{array}{l}\text { Net sulama suyu } \\
\text { ihtiyacı, dn (mm) }\end{array}$ & 65 & 64,2 & 71,1 & 60,4 & 58,8 & 57,2 \\
\hline $\begin{array}{l}\text { Toplam sulama suyu } \\
\text { ihtiyacı,dt (mm) }\end{array}$ & 73,7 & 72,8 & 80,6 & 68,5 & 66,6 & 64,9 \\
\hline $\begin{array}{l}\text { Aylık üç dönemin su } \\
\text { ihtiyacı (mm) }\end{array}$ & & 227,1 & & & 200 & \\
\hline
\end{tabular}

\subsection{Pompanın Modellenmesi}

Bölüm 2.3 ile bitkinin su ihtiyacı belirlendikten sonra gerekli su ihtiyacının karşılan- 
ması için uygun pompanın seçiminin yapılması gerekmektedir. Bu açıdan borulama tesisatının durumuna ve toplam yük kayıplarına göre pompaya verilmesi gereken işin bulunması ve doğru pompa seçiminin yapılması bu bölümde ele alınmıştır. Pompa motorunun tükettiği güç Denklem 20 ile hesaplanabilir.

$\dot{W}_{\text {pompa }}=\frac{\rho \dot{V} g h_{\text {toplam }}}{\eta_{\text {pompa-motor }}}$

Denklem 20 ile verilen, $\rho$ suyun yoğunluğu, $\dot{V}$ hacimsel debi, $h_{\text {toplam }}$ toplam yük kayb1, $\eta_{\text {pompa-motor }}$ pompa motor verimliliğidir ve bu değer genellikle yüzde 55 ile 85 arasında değişmektedir [17] Şekil 1 ile bir PV pompanın şematik gösterimi verilmiştir.

Denklem 20 içerisindeki toplam yük kaybı $\left(h_{\text {toplam }}\right)$ Denklem 21 ile belirlenir.

$$
h_{\text {toplam }}=h_{s}+h_{\text {düsüum }}+h_{B}+h_{b}
$$

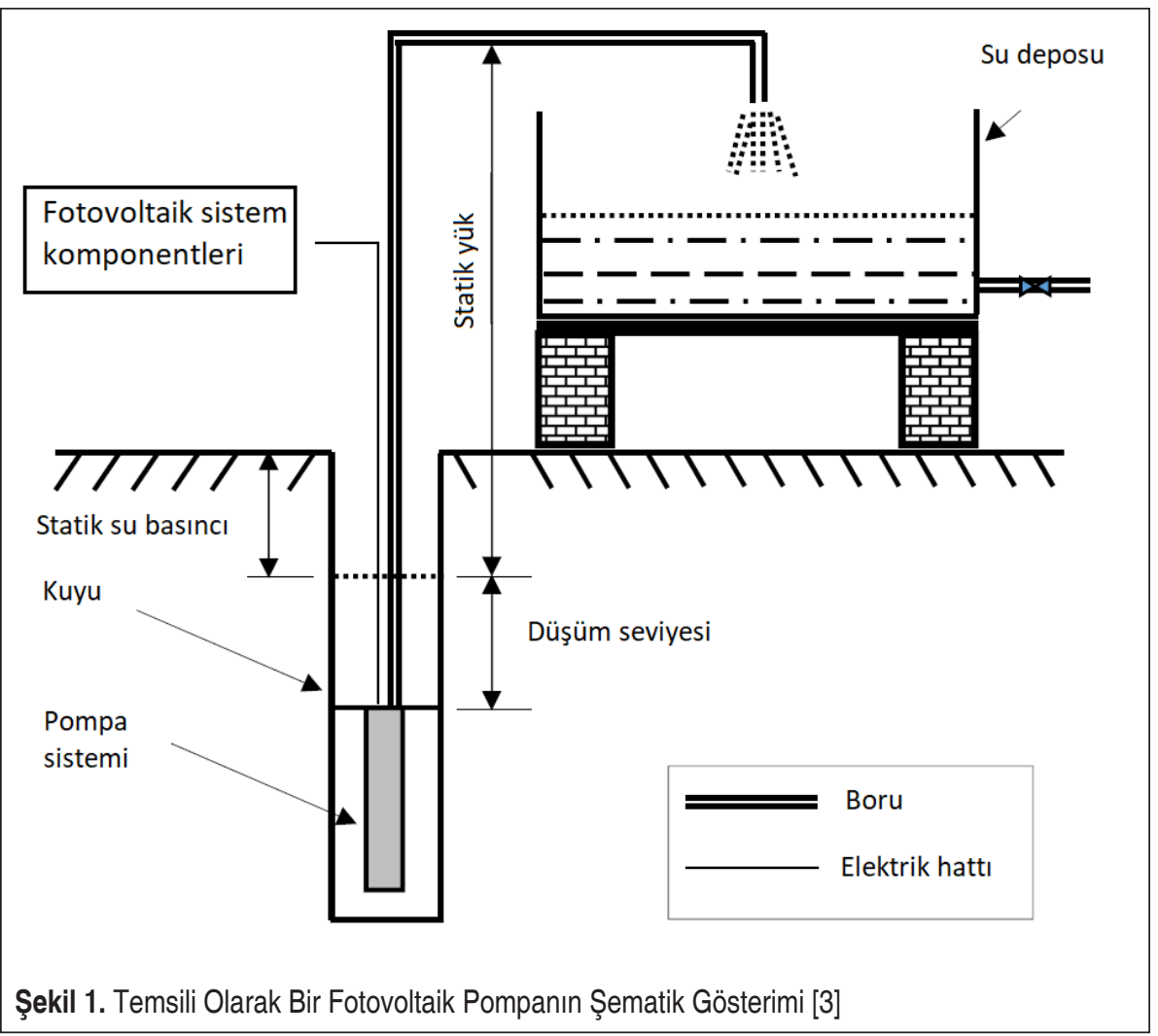


Denklem 21 ile verilen $h_{s}$, statik yüktür ve suyun yüzeyi ile deşarj noktası arasındaki farka eşittir, $h_{\text {düsüm }}$ düşüm seviyesi, $h_{B}$ boru hattındaki sürtünme kayıplarından kaynaklı yük kaybı (Denklem 22) ve $h_{b}$ bağlantı elemanlarındaki sürtünme kayıpları nedeniyle yük kaybıdır [3].

$$
h_{B}=f \frac{L v^{2}}{2 g d}
$$

Denklem 22 ile verilen $L$ boru uzunluğu, $d$ borunun iç çapı, $f$ Reynolds sayısına $(R e)$ bağlı boru hattının sürtünme faktörü, $v$ akışkanın hızıdır (Denklem 23).

$$
v=\frac{4 \dot{V}}{\pi d^{2}}
$$

Türbülanslı akış için sürtünme faktörü Denklem 24 ile hesaplanabilir.

$$
\frac{1}{\sqrt{f}}=-2,0 \log \left(\frac{\varepsilon / D}{3,7}+\frac{2,51}{\operatorname{Re} \sqrt{f}}\right)
$$

Ayrıca, $h_{b}$, Denklem 25 ile hesaplanabilmektedir. Denklemdeki $K_{k}$ kayıp katsayıs1 boru hattı içerisindeki komponentin tipine göre değişmektedir $[3,16]$.

$$
h_{b}=K_{k} \frac{v^{2}}{2 g}
$$

Bitkinin sulama suyu ihtiyacının karşılanabilmesi için pompa seçiminin uygun olarak yapılması gerekmektedir. Bu açıdan bu bölümde pompanın gücünün bulunabilmesi için temel eşitlikler Denklem (20-25) arasında verilmiştir. Çalışma kapsamında pompa seçimi, bir hazır seçim programı aracılığı ile belirlenmiştir [18]. Tablo 4 ile

Tablo 4. Seçilen Pompanın Özellikleri [18].

\begin{tabular}{|l|c|}
\hline Seçilen pompa özellikleri & Değeri \\
\hline Pompanın mil gücü & $1500 \mathrm{~W}$ \\
\hline Pompanın debisi & $9,55 \mathrm{~m} / \mathrm{h}$ \\
\hline Pompanın basma yüksekliği & $30 \mathrm{~m}$ \\
\hline Kütle & $19 \mathrm{~kg}$ \\
\hline Pompa malzemesi (Pompa, çark, motor) & Paslanmaz çelik \\
\hline
\end{tabular}


seçilen pompanın özellikleri verilmiştir. Toplam sulama ihtiyacı Bölüm 2.3 ile verilen hesaplamalar kullanılarak $9,55 \mathrm{~m}^{3} / \mathrm{h}$ olarak belirlenmiştir. Ek olarak, pompa seçimi için $h_{s}$ (statik yük) $20 \mathrm{~m}, h_{\text {düssum }}$ (düşüm yüksekliği) $5 \mathrm{~m}, h_{B}$ (borudaki sürtünme kayıplarından kaynaklı yük) 3,89 m ve $h_{b}$ (bağlantı elemanlarından kaynaklı yük kaybı) 0,2 m olarak hesaplanmıştır. Sonuç olarak toplam yük kaybı 29,1 m olarak hesaplamalara eklenmiştir.

\section{BOYUTLANDIRMA ALGORITMASI}

PV pompa sisteminin uygun ve optimum boyutlandırılması, sistem için gerekli olan enerji talebinin tam olarak karşılaması anlamına gelmektedir. Bu nedenle bitkinin yaşam döngüsü boyunca ihtiyaç duyduğu su miktarını, alanın coğrafi özelliklerinin, güneş 1şınımının, PV panelin özelliklerinin, akü kapasitesinin ve su deposunun boyutlarının uygun ölçütlerde hesaplanması ve belirlenmesi gerekmektedir. Hesaplamalar, akünün şarj ve deşarj arasındaki enerji dengesi üzerinedir. Böylelikle, ihtiyaç duyulan su hacminin pompalanması sağlanabilmektedir. Algoritmanın temel amacı, aküyü derin deşarj veya aşırı şarjdan korurken ve sulama için gereken su hacmini sağlarken gün boyunca yük beslemesini belirlemektir. PV pompa uygulamalarında, düzenekler hem akülü hem de aküsüz olarak kurulmaktadır [19]. Bu açıdan algoritma hem akülü sistemler için hem de akü içermeyen sistemler için uygulanmıştır. Algoritma, Şekil 2 ile gösterilen sistem için oluşturulmuştur. Algoritmanın şeması ise Şekil 3 ile verilmiştir. Algoritma, MATLAB programı kullanılarak gerçekleştirilmiştir.

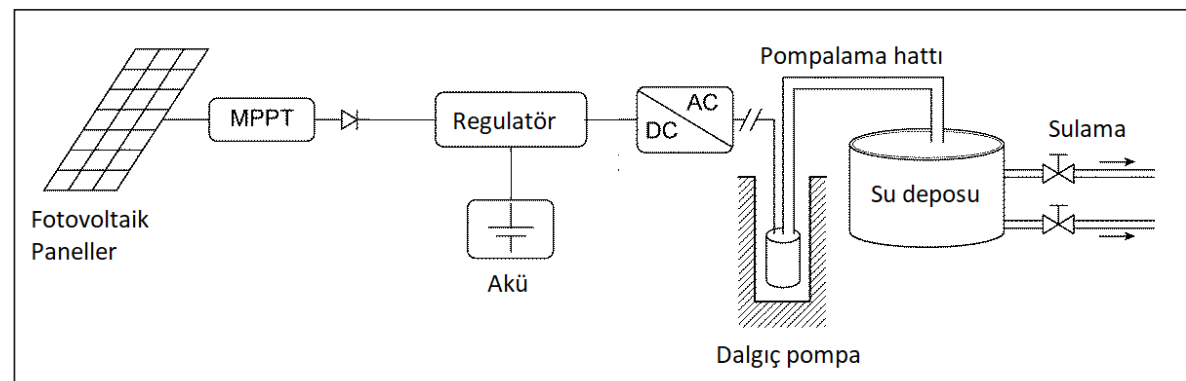

Şekil 2. Fotovoltaik Pompa Sistemi Bileşenleri [20]

Şekil 3 ile verilen boyutlandırma algoritmasının adımları aşağıda verildiği gibi düzenlenmiştir.

Adım 1. Bölüm 2.1'de Denklem 1 kullanılarak eğik yüzeye gelen 1şınımın hesaplanması gerçekleştirilmektedir.

Adım 2. Denklem 14 ile verilen panel veriminin hesaplanması yapılmaktadır. 


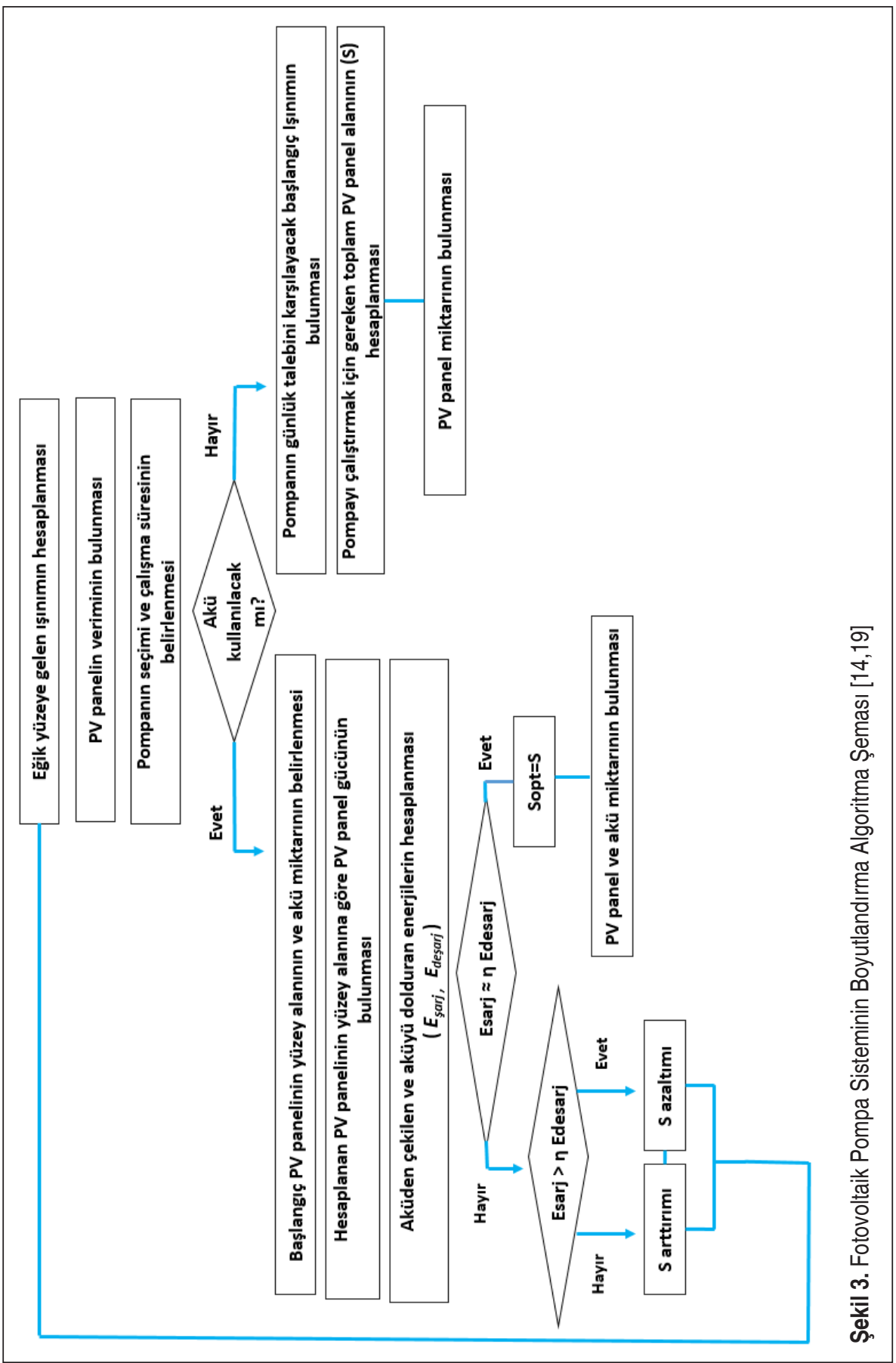


Adım 3. Bölüm 2.3 ile işlenen bitkinin hektar başına günlük su ihtiyacının hesaplanmasından sonra Bölüm 2.4'te gösterilen yöntem ile pompa seçimi yapılmaktadır. Böylelikle pompa gücü ve pompa çalışma süreleri hesaplanabilir.

Adım 4. Bu adımda genel algoritma, sistemde akünün kullanıp kullanılmayacağına göre iki farklı hesaplamaya yönlendirecektir.

\section{PV pompa sisteminin akü icermesi halinde:}

Adım 5. Başlangıç PV panelin yüzey alanı [14,19], toplam gücü ve akü miktarı sırasıyla Denklem 26, Denklem 27 ve Denklem 28 ile hesaplanabilir [19].

$$
S_{i}=\frac{\dot{W}_{\text {pompa }} \Delta t}{H_{T} n_{p v} \eta_{a k i \bar{u}}^{2} \eta_{\text {kablo }} \eta_{\text {reg }} \eta_{\text {inv }} \eta_{\text {birlesim }} \eta_{\text {opt }, \text { ssl }}}
$$

PV panelin toplam gücü Denklem 27 ile hesaplanmaktadır.

$$
P_{p v, i}=n_{p v} \eta_{r e g} \eta_{\text {birlesim }} \eta_{o p t, s s l} S_{i} I_{T}
$$

Denklem 26 ve 27 ile verilen $\eta_{a k i u}$ akünün elektriksel verimini, $\eta_{\text {kablo }}$ uyumsuz kablolama kayıplarını, $\eta_{\text {reg }}$ regulatör verimini, $\eta_{\text {inv }}$ invertör verimini, $\eta_{\text {birlesim }}$ panel eşleştirme verimini ve $\eta_{\text {opt, ssl }}$ panelin optik ve 1sıl performansını göstermektedir. Denklem 28 ile verilen $V_{a k i u}$ akü voltajını, $C_{a k u ̈}$ akünün kapasitesini ve $\Delta d o d_{\max }$ ise maksimum $d o d$ (derin deşarj) varyasyonunu temsil etmektedir.

$$
n_{b a t, i}=\frac{E_{s a r j}}{V_{a k i \bar{C}} C_{a k i u} \Delta d o d_{\max }}
$$

Çalışma kapsamında, $\eta_{a k u}=0,9, \eta_{\text {inv }}=0,975, \eta_{\text {kablo }}=0,95, \eta_{\text {birleșim }}=0,8, \eta_{\text {opt, lsll }}=0,9$, $\eta_{\text {reg }}=0,9$ ve $\Delta d o d_{\max }=0,78$ olarak hesaplara dahil edilmiştir. Akünün kapasitesi 210 Ah ve gerilim değeri $12 \mathrm{~V}$ olarak hesaplamalara eklenmiştir [19].

Adım 6. Denklem 26 ile hesaplanan panel alanına bağlı olarak panel gücünün hesaplanması gerekmektedir (Denklem 27).

Adım 7. Şekil 4 ile gösterilen aküden çekilen enerji miktarı $\left(E_{\text {desar }}\right)$ ve PV panel yardımıyla aküye aktarılan enerji $\left(E_{\text {şarj }}\right)$ hesaplanmaktadır. Ayrıca, aküyü derin deşarjlara karşı korumak amaçla algoritma içerisinde değerinin $(0,78)$ değerinden az olmasını sağlayan bir verimlilik $\eta$ katsayısı kullanılmıştır. Bu değer $\eta$ 1,28 olarak hesaplamalara dahil edilmiştir. Böylece, Denklem 29 ile akü üzerinden bir enerji dengesi elde edilmektedir [19]. 
$E_{\text {sarj }}=\eta E_{\text {desarj }}$

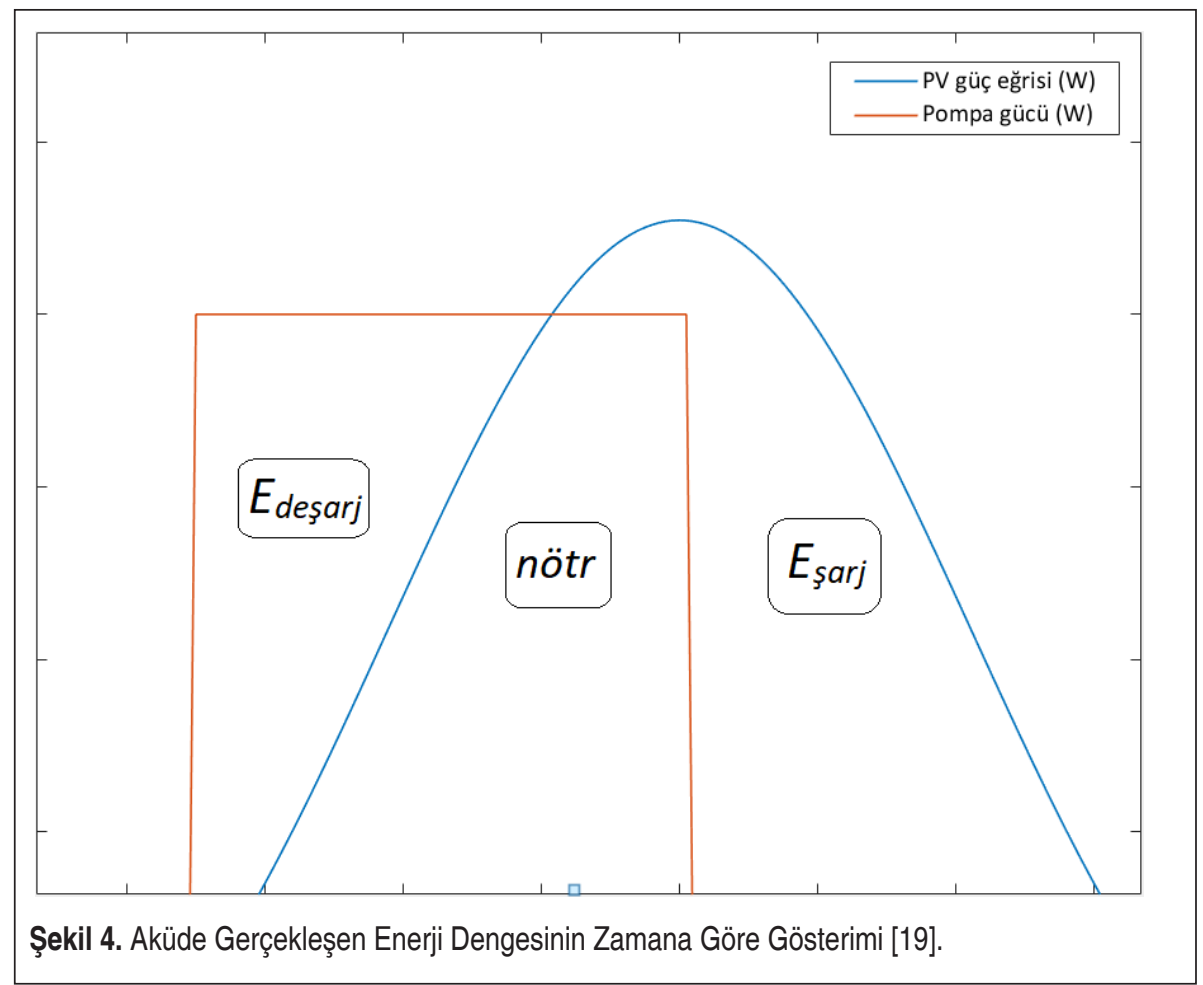

Adım 8. Denklem 29 ile değerlendirilir ve eğer Eşarj>Edeşarj ise panel yüzey alanı azaltılır, diğer durumda yüzey alanı arttırılır. PV panelinin artış veya azalış miktarı $0,25 \mathrm{~m}^{2}$ olarak belirlenmiştir. Eğer Eşarj ve Edeşarj yaklaşık birbirine eşit ise iterasyon durdurulur ve uygun panel alanı bulunmuş olur. Denklem (29) ile gösterilen eşitliğin iki tarafındaki fark, 50 W'dan düşük olduğu zaman iterasyon durmaktadır.

\section{Fotovoltaik pompa sisteminin akü icermemesi durumunda}

Adım 5. Şekil 5 ile gösterildiği gibi, öncelikle pompanın ihtiyacını karşılayacak ilk güneş 1şınım değeri $\left(I_{T, \text { ilk }}\right)$ bulunmalıdır [14].

Adım 6. Daha sonra, Denklem 30 kullanılarak pompayı çalıştırmak için gereken PV panel yüzey hesaplanır $[14,19]$.

$$
S=\frac{\dot{W}_{\text {pompa }} \Delta t}{I_{T, \text { ilk }} \Delta t n_{p v} \eta_{\text {kablo }} \eta_{\text {reg }} \eta_{\text {inv }} \eta_{\text {birlesim }} \eta_{\text {opt }, \text { ssl }}}
$$




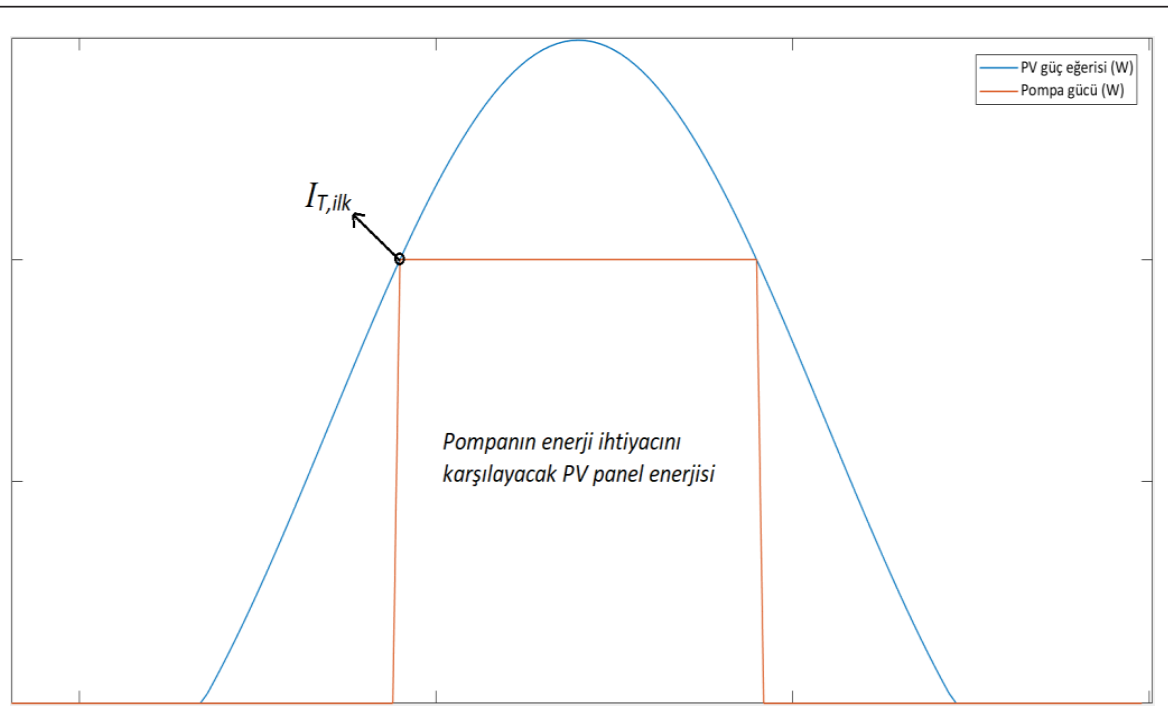

Şekil 5. . Pompa ile PV Panel Arasındaki Enerji Dengesinin Zamana Göre Gösterimi [14].

Denklem 30 ile verilen eşitlikte, Denklem 26'dan farklı olarak akü bulunmadığı için akü ile ilgili verim terimi çıkartılmıştır. Ayrıca, yataya gelen ışınım ile pompa çalışma süresinin çarpımı denkleme eklenmiştir (Şekil 5).

Adım 7. Böylelikle bulunan PV panel yüzey alanı seçilen pompanın enerji ihtiyacını karşılayabilecek kapasitede olacaktır. Yüzey alanını, bir adet PV panel yüzey alanına bölerek gerekli panel sayısı bulunabilir [14].

\section{ALGORİTMANIN DOĞRULUĞUNUN GÖSTERILMESİ}

Çalışma kapsamında oluşturulan fotovoltaik pompa sisteminin boyutlandırma algoritmasının doğruluğunun gösterilmesi için referans [19] kullanılmıştır. Tablo 5 ile her iki modelde çıkan önemli sonuçlar karşılaştırılmıştır. Referans alınan modelin iklim koşulları ve PV panel verileri, çalışmada oluşturulan model ile aynı değerde olacak şekilde hesaplamalar tamamlanmıştır.

Tablo 5 ile gösterildiği gibi, referans model ile çalışmada oluşturulan modelin verileri birbirine yakın çıkmaktadır. Bu açıdan, çalışma kapsamında oluşturulan modelin hesaplamaları geçerli olduğu kabul edilebilir. İki model arasında oluşan sayısal farklılıklar, boyutlandırma algoritmasının oluşturulma şeklinden, kullanılan formüllerin farklılığından ve çalışmada oluşturulan hesaplamalara bazı iklim verilerinin eklenmemesinden kaynaklanmaktadır. 
Tablo 5. Oluşturulan Model ile Referans [19]'daki Çalışmada Kullanılan Modelin Sonuçlarının Karşılaştırılması

\begin{tabular}{|l|c|c|c|c|c|c|c|c|}
\hline & \multicolumn{2}{|c|}{ Mart } & \multicolumn{2}{c|}{ Nisan } & \multicolumn{2}{c|}{ Mayıs } & \multicolumn{2}{c|}{ Haziran } \\
\hline Değerler & $\begin{array}{c}\text { Referans } \\
{[19]}\end{array}$ & Model & $\begin{array}{c}\text { Referans } \\
{[19]}\end{array}$ & Model & $\begin{array}{c}\text { Referans } \\
{[19]}\end{array}$ & Model & $\begin{array}{c}\text { Referans } \\
{[19]}\end{array}$ & Model \\
\hline $\mathrm{E}_{\text {desarj }}[\mathrm{Wh}]$ & 10991 & 10332 & 14481 & 14079 & 10239 & 12620 & 12511 & 11217 \\
\hline $\mathrm{E}_{\text {şarj }}[\mathrm{Wh}]$ & 18725 & 13488 & 23035 & 17336 & 16807 & 16232 & 18033 & 12636 \\
\hline $\mathrm{E}_{\text {pompa }}[\mathrm{Wh}]$ & 11258 & 11250 & 18615 & 18585 & 33350 & 33345 & 44716 & 44685 \\
\hline $\mathrm{S}\left[\mathrm{m}^{2}\right]$ & 37,5 & 34,34 & 41,5 & 45,78 & 54,5 & 77,97 & 61,5 & 90,99 \\
\hline $\mathrm{n}_{\text {bat }}$ [adet] & 4 & 5,35 & 5 & 6,88 & 4 & 6,44 & 5 & 5,01 \\
\hline
\end{tabular}

\section{ALGORITTMANIN BİR ÖRNEK ÜZERINNDE UYGULANMASI}

Bölüm 2.1 ile yataya gelen 1şınım değerleri verilmiştir. Bölüm 2.2 ile PV panel tipi ve panel verimliliği hesabı yapılmıştır. Bölüm 2.3 içerisinde, 1 hektarlık mısır bitkisinin günlük sulama suyu ihtiyac1 " $\mathrm{m}^{3}$ " cinsinden bulunmuştur. Bölüm 2.4 ile su ihtiyacına göre pompa seçimi yapılmıştır. Son olarak Bölüm 3 ile algoritmanın işleyişinin adımları anlatılmıştır. Bu bölümlerde belirlenen kriterlere göre, sistemde akü varlığında Tablo 6, akü olmadan Tablo 7 ile algoritma çıktılarının özeti verilmiştir. Tüm 1şınım ve ortalama hava sıcaklığı verileri Meteoroloji Genel Müdürlüğü resmi internet sitesinden alınmıştır [16].

Tablo 6. Algoritma Çıktı Özetleri (Akülü)

\begin{tabular}{|l|c|c|}
\hline Algoritma sonuçları & Miktar & Birim \\
\hline Gün içinde toplam PV panel alanına gelen toplam enerji & 182.587 & Wh/gün \\
\hline PV panelin güneşten elde edilebileceği maksimum enerji & 13.932 & Wh/gün \\
\hline PV sisteminin güneşten yararlanma oranı (panel, regülatör, akü vb.) & 7,63 & $\%$ \\
\hline Pompanın harcadığı toplam enerji & 12.600 & Wh/gün \\
\hline PV panel tarafından elde edilen ve israf edilen enerji & 1.332 & Wh/gün \\
\hline Aküden çekilen toplam enerji $\left(E_{\text {deşarj }}\right)$ & 3.887 & Wh \\
\hline Aküye gönderilen enerji $\left(E_{\text {şar) }}\right)$ & 4.995 & Wh \\
\hline Sistem için gerekli PV panel yüzey alanı & 27,62 & $\mathrm{~m}^{2}$ \\
\hline Sistem için gerekli PV panel miktarı & 23 & Adet \\
\hline Kullanılması gereken akü miktarı & 3 & Adet \\
\hline
\end{tabular}


Tablo 7. Algoritma Çıktı Özeti (Aküsüz)

\begin{tabular}{|l|c|c|}
\hline Algoritma sonuçları & Miktar & Birim \\
\hline Gün içinde toplam PV panel alanına gelen toplam enerji & 295.920 & Wh/gün \\
\hline PV panelin güneşten elde edilebileceği maksimum enerji & 25.210 & Wh/gün \\
\hline PV sisteminin güneşten yararlanma oranı (panel, regülatör vb.) & 8,95 & $\%$ \\
\hline Pompanın harcadığı toplam enerji & 12.600 & Wh/gün \\
\hline PV panel tarafından elde edilen ve israf edilen enerji & 12.610 & Wh/gün \\
\hline Sistem için gerekli PV panel yüzey alanı & 44,77 & m² \\
\hline Sistem için gerekli PV panel miktarı & 36 & Adet \\
\hline
\end{tabular}

Tablo 5 ve Tablo 6 ile PV pompa sisteminin, akülü ve aküsüz çıktı verilerinin özetleri gösterilmiştir. Sistemde akü kullanılmaması durumunda, PV panelin güneşten elde edilebileceği maksimum enerjinin neredeyse yarısının israf edilmiş olduğu görülmüştür. Ancak akü kullanılması durumunda, israf edilecek enerji depolanmaktadır ve sistem bu sayede daha iyi optimize edilebilmektedir.

\section{SONUÇ VE ÖNERÍLER}

Çalışma kapsamında geliştirilen PV pompa boyutlandırılması için oluşturulan algoritma çalışma kapsamında Manisa ili Salihli ilçesinde 1 hektarlık alanda mısır bitkisi için uygulanmıştır. Dahası, çalışmada oluşturulan algoritma, istenilen bölgeye ve bitkiye uygulanabilmektedir. Hesaplamaların tümü bir dalgıç pompa ve PV panel arasında gerçekleşen bir enerji dengesi kullanılarak gerçekleşmektedir. Sistemde akünün kullanılması neticesinde, PV panel miktarının önemli ölçüde düşürülebildiği hesaplanmıştır. PV panel sayısı düşürülmesi bir avantaj iken, akünün varlığı bir dezavantajdır. Gerçekte, bir fotovoltaik pompa sisteminin kurulabilmesi için, sadece en zor koşulları temel alan bir hesaplamadan ziyade, sistemin ekonomikliğinin daha fazla önem teşkil ettiği söylenebilir. Bu açıdan çalışma içerisine, daha kapsamlı meteorolojik veriler içeren yöntemler, su deposu hesaplamaları, daha kapsamlı sulama suyu ihtiyacı hesaplama yöntemleri ve en önemlisi ekonomik analiz eklenerek algoritma daha hassas ve doğru hale getirilebilir.

\section{KAYNAKÇA}

1. Abdelhak, B., Abdelhalim, B., Eddine, B. S., Layachi Z., Amor F., Brahami M. 2019. "Comparative Study on Photovoltaic Water Pumping Systems Driven by Direct Current 
Motor (DCM) and Induction Motor (IM) Optimized with P\&O Control”, AIP Conference Proceedings, 2190, p.020002-1-11.

2. Khatib, T., Mohamed, Sopian, A. K., Mahmoud M. 2011. "A New Approach for Optimal Sizing of Standalone Photovoltaic Systems", International Journal of Photoenergy, vol. 2012, no. 391213, p.1-7.

3. Muhsen, D. H., Khatib, T., Abdulabbas, T. E. 2018. "Sizing of a Standalone Photovoltaic Water Pumping System Using Hybrid Multi-Criteria Decision Making Methods", Solar Energy, vol. 159 p.1003-1015.

4. Allouhi, A., Buker, M.S., El-houari H., Boharb, A. Amine, M. B., Kousksou T., Jamil A. 2018. "PV Water Pumping Systems for Domestic Uses in Remote Areas: Sizing Process, Simulation and Economic Evaluation”, Renewable Energy, vol. 129, no.8, p.1-8.

5. Poompavai, T., Kowsalya M. 2019. "Control and Energy Management Strategies Applied for Solar Photovoltaic and Wind Energy Fed Water Pumping System: A review", Renewable and Sustainable Energy Reviews, vol. 107 p.108-122.

6. Campana, P. A., Li, H., Yan, J. 2013. "Dynamic Modelling of a PV Pumping System With Special Consideration on Water Demand, Applied Energy, vol. 112, p.635-645.

7. Kaldellis, J.K., Spyropoulos G.C., Kavadias K.A., Koronaki, I.P. 2009. "Experimental Validation of Autonomous PV-Based Water Pumping System Optimum sizing”, Renewable Energy, vol. 34 p.1106-1113.

8. Bakelli, Y., Arab, A. H., Azoui, B. 2011. "Imal Sizing of Photovoltaic Pumping System With Water Tank Storage Using Lpsp Concept”, Solar Energy, vol. 85, p.288-294.

9. Yahyaoui, I., Chaabene, M., Tadeo F. 2013. "An Algorithm for Sizing Photovoltaic Pumping Systems for Tomatoes Irrigation", International Conference on Renewable Energy Research and Applications, Electronic ISBN: 978-1-4799-1464-7.

10. Salam, M. A., Aziz A., Al-Waeli, A., Kazem, H. A. 2013. “ Optimal Sizing of Photovoltaic Systems Using HOMER for Sohar, Oman”, International Journal of Renewable Energy Research, vol. 3, no.2, p.301-307.

11. Ma, T., Yang, H., Lu L., Peng, J. 2014. "Pumped Storage-Based Standalone Photovoltaic Power Generation System: Modeling and Techno-Economic Optimization", Applied Energy, vol. 137, p.649-659.

12. Duffie, J. A., Beckman, W. A. Solar Engineering of Thermal Processes, Fourth Edition, John Wiley and Sons, ISBN 978-0-470-87366-3.

13. Habib, M.A., Said, S.A.M., El-Hadidy M. A., Al-Zaharna I. 1999. "Optimization Procedure of a Hybrid Photovoltaic Wind Energy System”, Energy, vol. 24, p.919-929.

14. Almarshoud A. F. 2016. "Sizing of PV Array for Water Pumping Application", 32nd European Photovoltaic Solar Energy Conference and Exhibition, At Munich, Germany. 
15. Tarımsal Araştırmalar ve Devlet Su İşleri Genel Müdürlüğü Politikalar Genel Müdürlügüü, 2016. "Türkiye'de sulanan bitkilerin bitki su tüketimi rehberi”, Ankara.

16. https://www.mgm.gov.tr (Erişim Tarihi 08.04.2020)

17. Çengel, Y., Cimbala, J.M. 2012. Akışkanlar Mekaniği Temelleri ve Uygulamaları, Güven yayınları, ISBN: 978-975-6240-18-2.

18. https://tr.grundfos.com/grundfos-for-engineers/videos-grundfos-product-center.html (Erişim Tarihi 05.04.2020)

19. Yahyaoui, I. 2016. Specifications of photovolta1c pumping systems in agriculture sizing, fuzzy energy management and economic sensitivity analysis, Elsevier inc., ISBN: 9780-12-812039-2.

20. Yahyaoui, I., Ammous, M., Tadeo F. 2015. "Algorithm for Optimum Sizing of a Photovoltaic Water Pumping System”, International Journal of Computer Applications, vol. 111 , no. 6, p.21-28. 